\title{
AERONAUTICAL RESEARCH: WIND TUNNELS, OLD AND NEW
}

$\mathrm{D}^{\mathrm{n}}$ . G. W. LEWIS, director of aeronautical research, National Advisory Committee for Aeronautics, U.S.A., delivered the Wilbur Wright Memorial Lecture before the Royal Aeronautical Society on May 25, taking as his subject "Some of 6 . Research up to to-day has universally confirmed that the assumption of these forms was correct to such an extent that it almost appears to have been an extension of their original work. Since this work was nerer published, these later

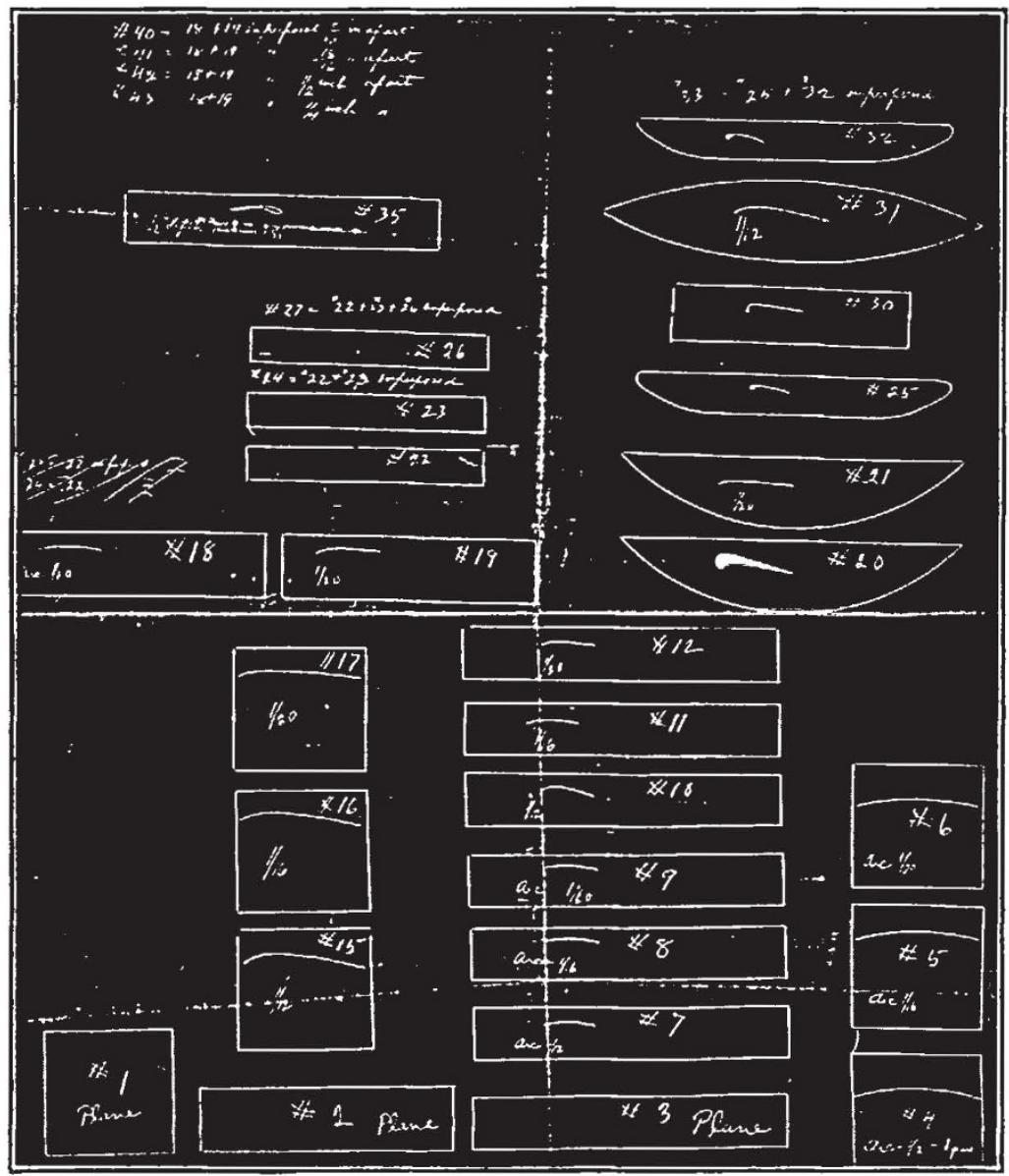

Fig. 1.

REPRODUCTION FROM THE WRIGIT BROTHERS' ORIGINAL RESEARCH prograysie (1901).

Modern Methods of Research in the Problems of Flight", with some personal reminiscences of the brothers Orville and Wilbur Wright, and gave some hitherto unpublished details of their original researches into the problems of flight in 1901. Fig. 1 shows profiles and plan forms of some of the aerofoils used by the Wrights in their wind tunnel. It can be seen that models 7,8 and 9 are circular arcs with a systematically varied camber, and 10,11 and 12 have a similar camber in a more forward location; also the models have a 1 -inch chord with a 6 -inch span, giving an aspect ratio day conclusions are an independent testimony to their far-sightedness and understanding of the basic principles.

The balances used in the Wrights' wind tunnel were ingeniously contrived in such a way that the fundamentally important requirements of obtaining readings that could be translated directly into effective forces upon a full-scale flying machine were given by direct readings, having reduced their critical assumptions to one. This was that the order of merit of the various shaped aerofoils would not be seriously affected by the Reynolds 


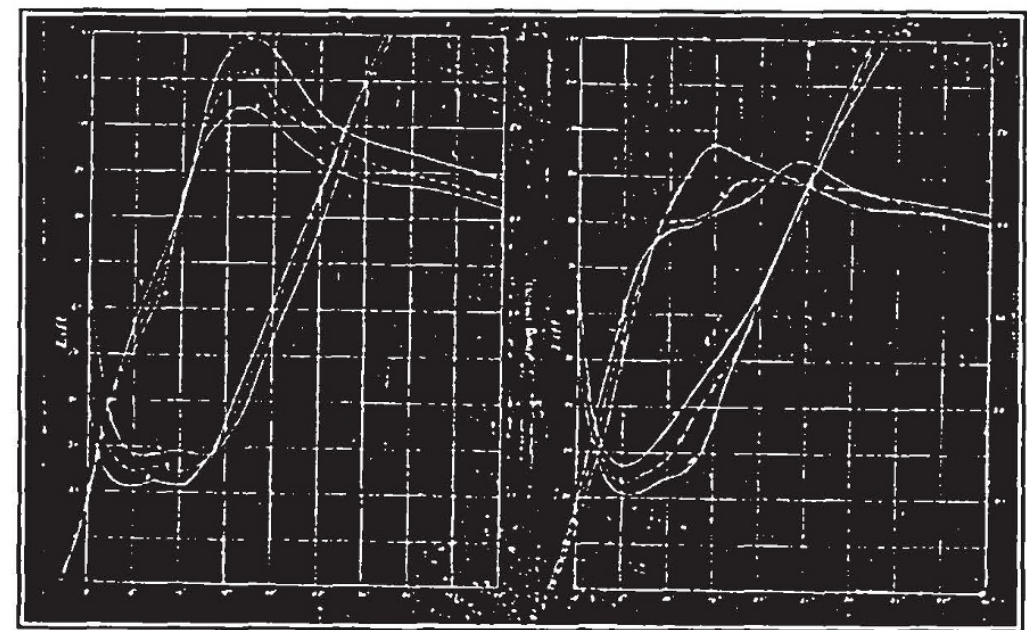

Fig. 2.

Rerroduction from original plots of DATA (1901).

conditions, and an 8-ft. 500 miles per hour wind tunnel. The most recent tunnel, designed in 1937, and now being placed in operation, is shown in Fig. 3 . This has a throat diameter of $19 \mathrm{ft}$., being able to accommodate large-scale models, and works up to speeds of 250 miles per hour at pressures from sub-atmospheric to several atmospheres.

There is a general trend towards the use of dynamic models for the investigation of stability and control problems, based on principles adopted originally by the Aeronautical Rescarch Committee in Great Britain at Farnborough. Also certain classes of investiga-

number of the experiment, although the absolute value of the coefficients would change. An actual case is worthy of mention in this respect. The Wright brothers, combining wind tunnel results and flight tests on their 1902 glider, found that the unit drag of a square flat plate was equal to the square of the speed, in miles per hour, multiplied by the coefficient 0.0033 . 'Io-day, after considerable research directed unon this question, the figure generally adopted is 0.00328 , a truly astonishing agreement.

Fig. 2 shows some results from the models 7,8 and 9 in Fig. 1, and the familiar shape of the lift and drag curves are such that they might well apply to many aerofoil forms in uso to-day.

Dr. Lewis then devoted the main part of his lecture to a description of the recent additions to the U.S.A. wind tunnels at Langley Field, the principal research station of the National Advisory Committee for Aeronautics. The general trend of improvements has been that of increase of size to allow the use of larger models, higher speed of the air stream to keep up with the increase of performance of actual aircraft, and provision for investigations at larger Reynolds numbers by the use of compressed air. Principally, the recent tunnels have been con. structed with the definite object of solving the problems that arise in aeroplane design. The most outstanding of these are, the variable density wind tunnel for research at high Reynolds numbers, the 20 -ft. propeller research tunnel, the full-scale tunnel, the high-speed jet tunnel for aerofoil research under propeller operating

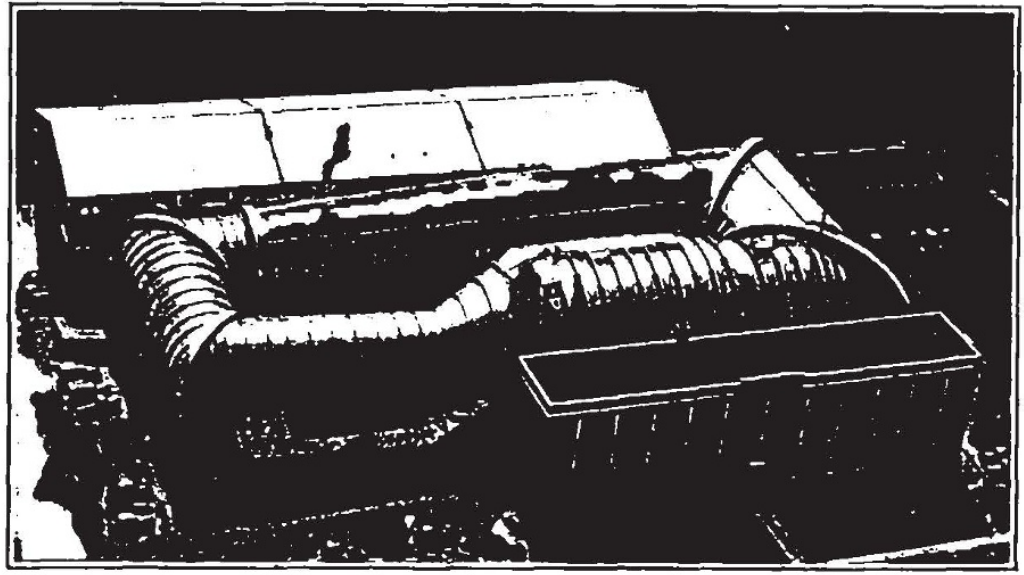

Fig. 3.

THE N.A.C.A. 19-FoOT PRESSURE TUNNEL. 
remain in a constant position rather than to move forward, as it does in turbulent wind tunnels, and thus an acrofoil could be designed to take advantage of true low-drag laminar boundary layers over a major portion of its surface. It is claimed that aerofoils so designed and tested in the lowturbulence wind tunnel are showing spectacular drag reduction, which should give valuable in. creases in speed, range, and general efficiency of aircraft.

Another problem that has been giving increasing concern to aircraft designers is that of the dynamic loading upon the structure due to accelerations consequent upon encountering atmospheric gusts. Increase in size and speed of the aeroplane both

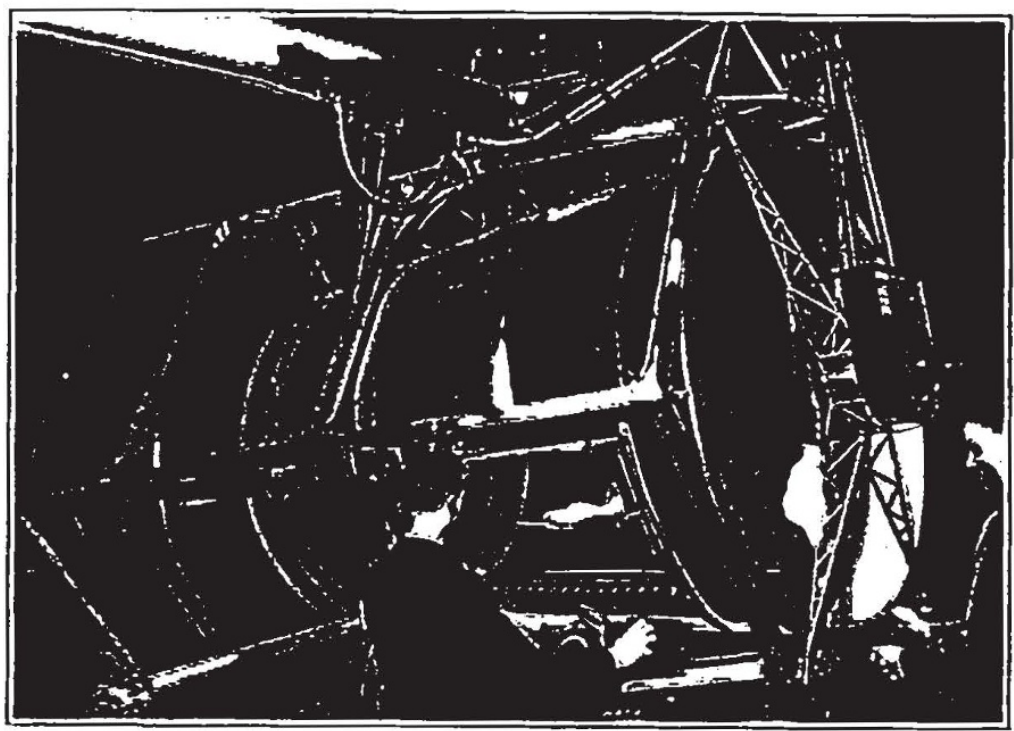

Fig. 5.

THE N.A.C.A. 5-FOOT FREE-FLIGIT TUNNEL IN OPERATION. accentuate this problem, and it is becoming obviously necessary to establish criteria for design against gust loads. The problem has been approached from two aspects. An instrument, known as the N.A.C.A. V-G recorder, was designed and installed in a number of machines, the total flying time of which, to date, approximates to 67,300 acroplane hours or 10 million miles, under as widely varying conditions of topography, weather, etc., as mossible. The instrument is seif-

recording, needs no attention from the aircraft's crew, and gives a simultaneous recording of accelerations and air speeds. Statistical results from these instruments suggest a probable maximum effective gust velocity of about 30 feet per second for an acroplane of the large flying boat type.

Upon this assumption, a 'gust tunnel' has been built in which it is possible to determine experimentally the reaction of suitably scaled dynamic models. It consists of an expand-

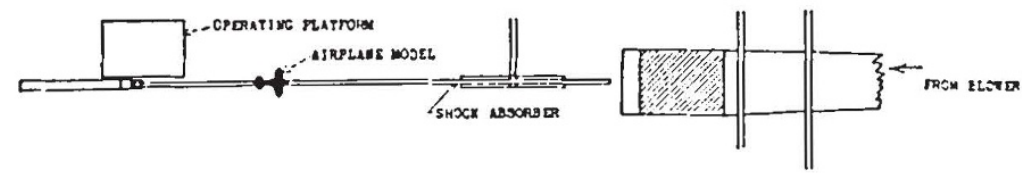
ing rectangular channel discharging a controlled current of air in an upward direction, see Fig. 4. A weight-driven catapult launches the model into a free glide at
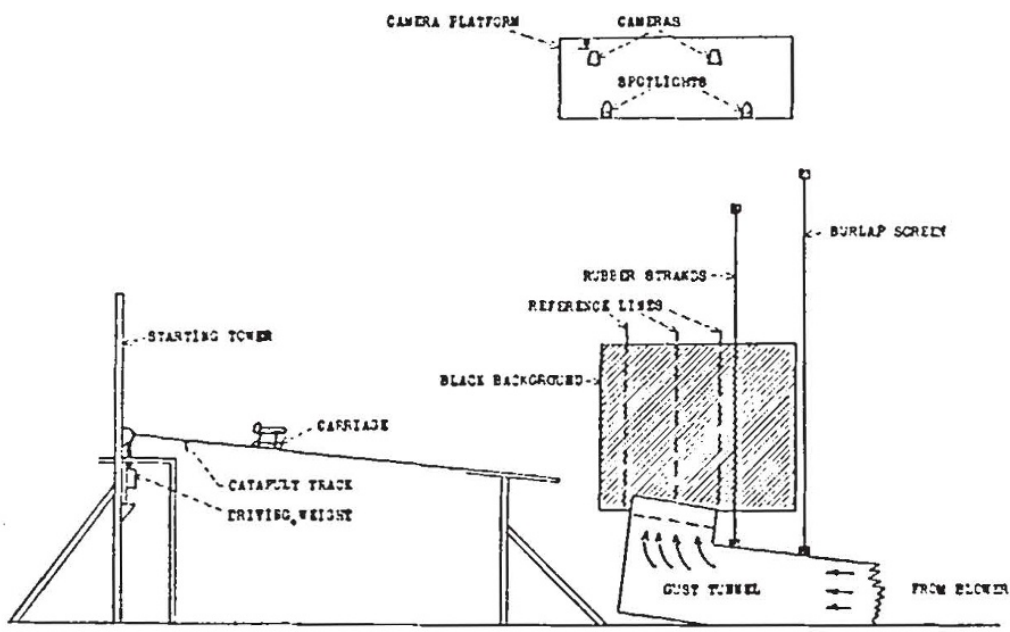

Fig. 4 .

Diagrax of the gust tunifil of the Nationat, Adusory Comittee For Aeronautics. constant speed, and when it enters the air jet it moves according to the changing forces imposed upon it. These movements are recorded photographically by light from small lamps at the nose and tail, and from these the movements of the centre of gravity and the pitching motion can be estimated. An accelerometer inside the model is synchronized with the photographic mechanism, so that the two records can be correlated.

The general problem of stability and control in flight is also being dealt with in a more precise manner than hitherto by means of $\Omega$ free-flight wind tunnel. The body of the tunnel is $5 \mathrm{ft}$. in 
diameter, provided with a normal fan giving air speeds up to $25 \mathrm{ft}$. per second. It is suspended on trunnions so that its inclination can be varied, and an operator maintains the inclination and air speed in proper co-ordination with the gliding characteristics of the model under test. A second operator manipulates the controls of the model, governed by small electro-magnets inside its body, by a series of switches connected to the model by a fine wire of length sufficient to hang slack and allow the model to perform any manœuvre unrestricted. Fig. j shows this tunnel with a model in free flight inside it.

\section{PRIESTLEY AND LAVOISIER}

$\mathrm{T}$ TWO lectures delivered by Sir Philip Hartog at University College, London, on May 9 and 16 dealt with "The Newer Views on Priestley" and Lavoisier", these being given under the scheme for advanced lectures of the University of London.

It was pointed out that the usual estimates of Priestley's work are based on too little acquaintance with his writings, and do not do him sufficient justice. The work of Lavoisier is now better understood, largely by reason of the publications of the late Dr. A. N. Meldrum, and Sir Philip was concerned with some aspects of the relations between Priestley and Lavoisier.

Priestley's carly work on electricity is contained in his "History of Electricity", first published in 1767 and written in a year. This shows him making quantitative experiments and putting forward hypotheses which Sir Philip Hartog thinks were based on what Priestley calls the "bold eccentric thoughts of the Queries in the Opticks" of Newton. Priestley's first thoughts on chemistry are also to be found in this book, and in it he describes some experiments on mephitic air and charcoal, the mephitic air being made by passing air over heated charcoal. After finding that a candle would not burn in air that had passed through a charcoal fire, or through the lungs of animals, Priestley says: "I was considering what kind of change it underwent, by passing through the fire, or through the lungs, etc., and whether it was not possible to restore it to its original state, by some operation or mixture". 'This early work provides a key to Priestley's later studies on gases, beginning with those published in 1772 .

When Priestley began his work, there were three special pitfalls into which an investigator on gases could stumble, as well as the general bar to progress set by the phlogiston theory: (1) it was not known whether heat was ponderable or not, (2) it was not known whether light was ponderable or not, (3) permanent gases were regarded as essentially different from solids and liquids. Hales, in his "Vegetable Staticks" (1727), had failed to differentiate gases from air, and although Bocrhaave in his "Elements of Chemistry"
(1731) speals as though he distinguished between the different varieties of air-including van $\mathrm{Hel}$. mont's gas sylvestre (carbon dioxide)-yet it was Black and Cavendish, in 1756 and 1766 respec. tively, who sharply differentiated fixed air (carbon dioxide) and inflammable air (hydrogen). Priestley discovered a number of new 'airs', some of which he collected over mercury, and his publications on these begin in 1772. The airs discovered by Pricstley were stated by Sir Philip to be : hydrogen chloride, nitrogen, nitric oxide, nitrous oxide, nitrogen peroxide (which he collected by downward displacement), ammonia, sulphur dioxide, silicon fluoride, oxygen and hydrogen sulphide, all discovered in the period 1772-1790. After his long paper in the Philosophical Transactions in 1772, Priestley published his work on gases in his books: "Experiments and Observations on Different Kinds of Air" (3 vols., 1774-77), "Experiments and Observations relating to various branches of Natural Philosophy with a continuation of the Observations on Air" (3 vols., 1779-86), and "Experiments and Observations on Air" (3 rols., 1790). These volumes are a rich mine of experimental results.

Of Lavoisier, Sir Philip said: "From the first Lavoisier's work is distinguished from that of Priestley and many other predecessors, not by the use of the balance as is often stated, for Priestley was quite capable of using the balance and to excellent purpose, but by the systematic use of the balance in checking chemical reactions, especially in dealing with gascous reactions". In his earlier work (November 1772), Lavoisier had discovered that in the combustion of sulphur and phosphorus, air is absorbed and the combustible increases in weight. He was also persuaded that the increase of weight of a metal during calcination is caused by absorption of air. In 1792 Lavoisier wrote: "It is easy to see that from the year 1772 I had conceived the doctrine of combustion as a whole". In February 1773 (not 1772, as Lavoisier himself, by a slip of the pen, dated his memo. randum), he proposed to make a long series of experiments on gases, and in his "Opuscules 